\title{
Higiene para as escolas primárias: a produção escrita de Antonio Ferreira de Almeida Júnior (1922-1939)
}

\author{
Angélica Pall Oriani ${ }^{1}$ \\ ORCID: 0000-0003-3647-6820
}

\section{Resumo}

Nos projetos de intervenção elaborados, em São Paulo, durante as primeiras décadas do século XX, a saúde e a educação foram alçadas a pilares sobre os quais repousava um programa para regenerar a sociedade. Este artigo insere suas discussões nesse cenário e problematiza os saberes sobre higiene propostos para as escolas primárias a partir dos textos de Antonio Ferreira de Almeida Júnior (1892-1971). Professor, médico e administrador da educação, ele não somente defendeu e recomendou programas voltados para o ensino de higiene, como também ocupou cargos que lhe garantiram a condição de agente propositor e divulgador desses preceitos. Como recorte cronológico, consideramse os anos entre 1922 e 1939, período em que o professor escreveu e publicou textos de naturezas diferentes nos quais abordou a importância dos conteúdos de higiene nas escolas. A produção bibliográfica de Almeida Júnior foi analisada em paralelo à sua atuação profissional, o que permitiu compreender a participação do professor nos debates médico-educacionais, os quais, de modo bastante pontual, defendiam um projeto político que tinha como lema "sanear a população pela escola". Com isso, constata-se que, em seus escritos sobre educação, Almeida Júnior matizou representações da natureza infantil, formuladas a partir da ideia de plasticidade cerebral, às suas concepções acerca das finalidades da escola primária e da modificação na formação de professores a partir da incorporação de novos programas e de métodos de ensino mais ativos.

\section{Palavras-chave}

Escola primária - Higiene - Almeida Júnior (1892-1971).

1- Universidade Estadual Paulista "Júlio de Mesquita Filho", Marília, SP, Brasil. Contato: angelicaoriani@hotmail.com

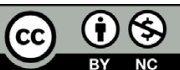




\section{Hygiene for primary schools: the written production of Antonio Ferreira de Almeida Júnior (1922-1939)}

\section{Abstract}

In intervention projects developed during the first decades of the 20th century in São Paulo, health and education were raised to pillars on which laid a program to regenerate society. This article includes its discussions in this scenario and discusses the knowledge of hygiene proposed for primary schools based on the written production of Antonio Ferreira de Almeida Júnior (1892-1971). Professor, physician, and education administrator, he not only defended and recommended programs aimed at teaching hygiene, but he also held positions that guaranteed him the condition of an agent that could propose and disseminate these precepts. As a chronological cutout, the years between 1922 and 1939 were considered. During this period, this professor wrote and published texts of different kind in which he addressed the importance of hygiene content in schools. Almeida Júnior's bibliographical production was analyzed in parallel with his professional performance, which allowed us to understand his participation in medical-educational debates, which, quite punctually, defended a political project whose motto was "to clean up the population through school". Thus, it appears that, in his writings on education, Almeida Junior nuanced representations of childhood nature, formulated from the idea of brain plasticity, into his conceptions about the purposes of primary school and the change in teacher education based on absorbing new programs and more active teaching methods.

\section{Keywords}

Primary school - Hygiene - Almeida Júnior (1892-1971).

\section{Curar uma nação doente a partir da escola}

Em São Paulo, no começo do século XX, médicos, educadores e administradores lastimavam que as precárias condições higiênicas em que a população vivia a deixava exposta a doenças infectocontagiosas, as quais grassavam no território. Como solução diante desse cenário, a regeneração das crianças, vislumbrada por meio da educação sanitária, foi mote de campanha a partir da qual se entrelaçavam demandas que visavam forjar hábitos para corporificar a higiene e moldar corpos e mentes (ROCHA, 2003a).

Dentre os intelectuais engajados na reflexão e na disseminação de preceitos de higiene por meio da escola primária, destaco Antonio Ferreira de Almeida Júnior (18921971), professor, médico e administrador da educação que atuou, de modo intenso, durante as primeiras décadas do século XX, produzindo materiais pedagógicos, formando professores e contribuindo para a elaboração de políticas sanitário-educacionais, que tinham por lema sanear a sociedade pela escola. 
Neste artigo, exploro os saberes sobre higiene destinados à escola primária ${ }^{2}$ conforme pensados e tematizados pelo professor. No conjunto de seus escritos, selecionei a tese 0 saneamento pela educação (1922) - defendida na Faculdade de Medicina e de Cirurgia de São Paulo -, a Cartilha de higiene (1923), o livro Noções de puericultura (1927) - escrito em coautoria com Mario Mursa -, o livro Elementos de anatomia e fisiologia humanas (1931) e o livro Biologia educacional: noções fundamentais (1939). Sobre as opções dessa escolha, valem alguns esclarecimentos: apesar de as assimetrias quanto às finalidades, aos leitores almejados e aos usos dados a esses textos imprimirem a eles destinos diferentes (CHARTIER, 1991), o roteiro por meio do qual higiene e educação se relacionam os aproxima.

Considero que esses escritos concretizam um conjunto de saberes no qual Almeida Júnior articulou representações da natureza infantil às suas concepções acerca das fınalidades da escola primária e do professor no que concerne à educação higiênica.

É preciso destacar, porém, que o recorte na produção de Almeida Júnior não desconsidera que, ao longo de 1920 e de 1930, ele também publicou trabalhos em encontros científicos, dos quais participou de modo intenso (VIVIANI; MARCHAN, 2008). Esse recorte delineia limites e toma os textos supracitados como cruciais para o exercício reflexivo, bem como considera outros materiais como auxiliares à compreensão das ideias sobre higiene que Almeida Júnior defendia naquele momento, até mesmo porque, de modo mais ou menos pontual, as questões abordadas nos trabalhos apresentados em eventos foram desenvolvidas ou retomadas nos livros que selecionei como corpus para investigação.

A leitura de seus textos também se apoia nas reflexões já desenvolvidas a respeito de sua produção escrita, especialmente por Viviani (2005, 2007), Viviani e Marchan (2008), Rocha (2003a, 2003b, 2011) e Morando e Souza (2019). De modo geral, esses autores identificam o uso estratégico do impresso pedagógico por Almeida Júnior para legitimar sua posição social privilegiada como médico, educador e gestor. Acrescento a essas contribuições as perspectivas do olhar direcionado ao conjunto de textos do professor em que foram forjadas suas concepções sobre higiene, pensadas pedagogicamente (HÉBRARD, 1990) e mobilizadas por meio da formação de professores.

A ação de mapear os dispositivos utilizados para materializar os preceitos sanitários destinados à escola é considerada no âmbito de sua fertilidade no movimento de identificação da circulação de tais saberes, assim como atesta Carvalho (2011). Nos itinerários percorridos, vislumbram-se os modos por meio dos quais tais impressos normatizaram as práticas escolares. Ao mesmo tempo, os caminhos trilhados pelo próprio Almeida Júnior o situam como agente que circulou e que fez com que os saberes circulassem.

\section{Almeida Júnior: the right man in the right place ${ }^{3}$}

Nascido em Joanópolis (SP), Almeida Júnior formou-se professor, em 1909, na Escola Normal da Praça da República, em São Paulo. Iniciou sua carreira como docente

\footnotetext{
2- As reflexões exploradas neste artigo decorrem de desenvolvimento de pesquisa de pós-doutorado na Universidade Estadual Paulista "Júlio de Mesquita Filho", campus de Marília, sob a supervisão da profa. dra. Ana Clara Bortoleto Nery.

3- As contribuições de Gandini $(2005,2010)$ foram essenciais para a escrita desta seção.
} 
no ensino primário, em 1910, e, entre 1911 e 1914, lecionou francês na Escola Normal de Pirassununga, onde foi professor de Lourenço Filho.

Em 1913, solicitou licença na Escola Normal e viajou à Europa após receber parte da herança da mãe. Segundo seu relato, $O$ banho de civilização que recebeu durante os seis meses de viagem abriu-lhe horizontes, fazendo-o repensar sua volta a Pirassununga. Buscando novos ares, Almeida Júnior decidiu ir para a capital do estado, onde poderia tentar o vestibular para cursar medicina.

Em 1921, com 30 anos, Almeida Júnior formou-se médico, tendo se doutorado, no ano seguinte, pela Faculdade de Medicina e Cirurgia de São Paulo. Sua tese, O saneamento pela educação (1922), versava sobre a urgente necessidade de operar modificações na escola primária para que ela realizasse a educação da criança de acordo com normas sanitárias e higiênicas que deveriam ser inculcadas como hábitos.

De acordo com Gandini (2010), Almeida Júnior relata, em suas memórias, ter ficado indeciso quanto ao caminho que seguiria após a formação médica, para o que contribuíram as relações que estabeleceu com médicos que compunham o quadro de docentes da área de saúde pública junto à faculdade supracitada e com intelectuais que ocupavam cargos na administração da educação.

É interessante notar a circulação de Almeida Júnior e as relações que ele teceu e que, de certo modo, o dispuseram profissionalmente junto de outros indivíduos, cujas atuações foram cruciais no que se refere à proposição de políticas educacionais e sanitárias em São Paulo, especialmente durante o período delimitado. Ao olhar para o grupo de intelectuais e pensadores da educação com os quais ele se relacionava, nota-se a articulação com Fernando de Azevedo, Lourenço Filho e outros defensores do movimento da Escola Nova no Brasil. Por esse motivo, ele foi convidado a assumir o cargo de diretor de ensino de São Paulo entre 1935 e 1937; posição notória em razão dos poderes administrativos que lhe foram conferidos em um período no qual grupos diferentes disputavam o controle e a implantação de modelos de educação (CARVALHO, 1998).

Porém, antes de explorar os laços entre Almeida Júnior e outros intelectuais, é preciso acrescentar outros atores, ações e instituições ao cenário em que as ideias higienistas e sanitaristas ganhavam destaque.

\section{Defesa e disseminação da educação higiênica: espaços e tempos}

Em 1918, foi criado o Laboratório de Higiene, órgão que se instituiu de modo alinhado ao modelo norte-americano no que se refere à saúde e como resultado de acordo assinado entre o Governo do Estado de São Paulo e a Junta Internacional de Saúde da Fundação Rockefeller ${ }^{4}$ (ROCHA, 2003a). Esse acordo tinha como objetivo prover a cadeira de Higiene da Faculdade de Medicina e Cirurgia de São Paulo. Segundo

4- A Fundação Rockefeller foi fundada nos Estados Unidos, em 1913, com o objetivo de promover, no exterior, 0 estímulo à saúde pública, à pesquisa e à filantropia. Caracterizou-se pelo fato de ser uma instituição não governamental e utilizar-se de recursos próprios para realizar ações em países em desenvolvimento. 
Rocha (2003a), o papel do laboratório foi crucial à formulação de políticas sanitárias no estado, tornando-se instituto em $1919^{5}$.

Ainda em 1918, foi realizado um curso de Higiene Pública destinado aos diretores de grupos escolares de todo o estado. A ideia era divulgar, capilarmente, os conhecimentos de higiene adquiridos pelos diretores, nas várias escolas espalhadas pelo interior e pelo litoral de São Paulo. 0 curso foi uma sugestão de Oscar Thompson, então diretor da Instrução Pública, a Rodrigues Alves, secretário do Interior do Estado, que a acatou prontamente.

De acordo com Bertucci (2006), o saneamento do interior paulista era uma preocupação latente nas décadas iniciais do século XX, pois, à medida que a expansão cafeeira e o avanço da estrada de ferro se direcionaram para o oeste do estado, tornou-se necessário aumentar os esforços para evitar a proliferação de mosquitos e de doenças, que ameaçavam e vitimavam a população.

No Instituto Butantã e sob a batuta de seu diretor, Vital Brazil, o curso de Higiene Pública compôs o conjunto de ações que se levava à frente no estado de São Paulo, visando agir para a propagação da higiene. 0 curso contou também com o apoio de Arthur Neiva, que ocupava o cargo de diretor do Serviço Sanitário do Estado de São Paulo, e de Antônio de Sampaio Dória, que seria convidado, em 1920, a ser diretor da Instrução Pública.

A epidemia de gripe espanhola, que atingiu a população brasileira em 1918, também repercutiu de forma decisiva no funcionamento das cidades e da vida cotidiana. As crises geradas em eventos epidêmicos expõem as fragilidades e as inadequações do serviço sanitário em responder com eficácia às demandas por atendimentos. No estado de São Paulo, as instabilidades foram cruciais para o convite a Geraldo de Paula Souza para assumir a direção do Instituto de Higiene e do Serviço Sanitário de São Paulo em 1922. Tendo retornado, de um doutorado em Higiene e Saúde Pública na Universidade Johns Hopkins. 0 médico redefiniu o modelo de política sanitária no estado de São Paulo por meio da Reforma do Código Sanitário, publicada em 1925 (ROCHA, 2003a).

No âmbito desse instituto, a partir de 1921, Almeida Júnior tornou-se bolsista da Junta Internacional de Saúde, mantida pela Fundação Rockefeller, condição que lhe permitiu estar à frente do departamento de Higiene Escolar (BERTUCCI, 2013; ROCHA, 2003a) e trabalhar em parceria com Geraldo de Paula Souza, que havia sido seu professor na Faculdade de Medicina e Cirurgia.

Como se observa, as redes que estavam sendo tecidas nesse momento apontam não somente à aproximação entre o Instituto de Higiene e a Secretaria de Serviço Sanitário (ROCHA, 2003a), mas também entre eles e a Diretoria da Instrução Pública por meio das relações existentes entre Almeida Júnior e Antônio de Sampaio Dória.

A partir de 1919, e durante o período em que Sampaio Dória ocupou o cargo de diretorgeral de Ensino, Almeida Júnior foi seu chefe de gabinete, chefiando o recenseamento escolar do estado e participado, de modo assíduo, na elaboração da Reforma de 1920 (GANDINI, 2005, 2010). Dentre as várias implicações da Reforma, para os fins deste artigo vale destacar que a partir dela foi incluída a cadeira de Anatomia e Fisiologia Humana, Biologia e Higiene como uma das que deveriam compor a formação dos futuros professores (ROCHA, 2003a).

5- Em 1924, o Instituto de Higiene tornou-se independente da Faculdade de Medicina e Cirurgia de São Paulo, e, em 1969, foi transformado na Faculdade de Saúde Pública da Universidade de São Paulo. 
Sobre essa inclusão, é importante destacar a possível influência de Almeida Júnior, já que, entre 1920 e 1930, ele também atuou como professor na Escola Normal do Braz, lecionando as disciplinas de Biologia Educacional e Higiene.

Nota-se que debates acerca da importância da higiene escolar na formação do professor se fortaleceram e puderam ser capitaneados a partir da atuação de Almeida Júnior, que ocupava cargo no Instituto de Higiene, na Escola Normal do Braz e na administração da educação. Tanto que, sob a tutela da Reforma Sampaio Dória, Almeida Júnior elaborou e aplicou um programa de higiene aos alunos do quarto ano da Escola Normal do Braz, uma vez que a autonomia docente havia sido permitida pela Reforma de 1920, desde que os programas e planos de ensino fossem aprovados pelo diretor da instituição.

Esse programa de ensino foi apresentado pelo professor como proposta de abordagem da temática da higiene na tese defendida em 1922. Com isso, diferentemente do curso realizado com os diretores de grupos escolares no Instituto Butantã, em 1918, o programa de Almeida Júnior atingia os professores em formação.

As preocupações de Almeida Júnior com as questões educacionais e com a higiene se mantiveram intensas ao longo da década de 1930, e parte de suas propostas pedagógicas puderam ser legitimadas justamente pelo fato de ele transitar e se relacionar de forma intensa com o grupo de educadores e intelectuais que ocupava cargos e posições à frente do movimento que disputava a cena educacional naquele momento, assim como pelo fato de ter atuado como formador de professores primários, que o permitiu colocar em prática algumas de suas proposições pedagógicas.

Em 1932, Almeida Júnior assinou com Fernando de Azevedo, Lourenço Filho, Anísio Teixeira, e outros, o Manifesto dos pioneiros da educação nova. Em 1933, foi nomeado chefe do Serviço de Saúde Escolar do Estado de São Paulo, cargo no qual permaneceu por seis meses (VIVIANI; MARCHAN, 2008), e auxiliou Fernando de Azevedo na elaboração do Código de Educação de São Paulo. Ainda em 1933, foi transferido da Escola Normal do Braz para o Instituto de Educação Caetano de Campos, onde lecionou a disciplina de Biologia Educacional.

Em 1934, colaborou no processo de criação e institucionalização da Universidade de São Paulo. Em 1935, foi nomeado diretor do Ensino do Estado de São Paulo; contudo, em abril de 1938, desligou-se do cargo devido ao golpe de estado que instaurou a Ditadura $\operatorname{Vargas}^{6}$ (GANDINI, 2010).

Além de a atuação profissional de Almeida Júnior evidenciar que as posições e os cargos que assumiu lhe permitiram circular, sua produção bibliográfica fez com que suas ideias também circulassem. Durante as décadas de 1920 e 1930, foram intensas suas defesas em prol de programas de formação de professores calcados em conhecimentos sólidos de higiene, os quais estariam articulados com suas representações acerca da infância e o papel da escola como promotora de hábitos saudáveis.

Portanto, considero a tese de Almeida Júnior, pelo tipo de texto, pela finalidade, assim como pelo leitor a que se destinava, como o texto em que ele concretizou

6- Vale destacar que Almeida Júnior continuou atuando na área educacional nas décadas seguintes, exercendo funções políticas, administrativas e docentes. 
teoricamente suas proposições acerca da educação higiênica, em que as escolas primárias seriam essenciais, assim como os professores, os quais deveriam ser formados a partir de programas renovados de higiene e com conhecimentos da natureza infantil. Na sequência, os manuais didáticos que escreveu e publicou, e que eram destinados às crianças ou aos professores em formação, organizam pedagogicamente os saberes sobre higiene e, portanto, contribuem para os processos de pedagogização de tais saberes e de normatização das práticas escolares.

Destarte, para os fins deste texto, o lugar que a higiene e a educação ocupam na produção escrita de Almeida Júnior é considerado a partir de dois caminhos que se cruzam: as representações acerca da infância e da escolarização; e a formação de professores a partir de conteúdos e métodos renovados.

\section{Educação higiênica na escola primária: a criança e a formação do hábito}

Atuando como assistente pensionado no Instituto de Higiene desde 1921, Almeida Júnior escreveu sua tese versando sobre o saneamento pela educação. Em suas linhas, a tese lançou as bases sob as quais se sustentariam as defesas levadas adiante pelo Instituto em torno de uma educação higiênica mais formativa e consciente e menos policialesca e punitiva.

A influência de $O$ saneamento pela educação, contudo, não se limitava ao âmbito do Instituto, porque, entre 1922 e 1927, o órgão assumiu lugar de destaque na formulação das políticas sanitárias no estado, participando decisivamente da produção de um discurso científico sobre tais questões e da elaboração de estratégias de intervenção que colocavam a educação sanitária em primeiro plano como instrumento de higienização da população (ROCHA, 2003b). Tais estratégias se alinhavam a modelos norte-americanos e eram sustentadas por Geraldo de Paula Souza na direção do Instituto do Serviço Sanitário.

Em suas 78 páginas $^{7}$, a tese de Almeida Júnior capitaneia os debates postos pelas campanhas de saneamento e pró-higienistas, concretizando algumas das linhas mestras do que se desenvolvia no âmbito do instituto ${ }^{8}$. Diante das certezas a respeito da educação como ferramenta crucial para combater doenças, Almeida Júnior considerava que a escola primária reunia os brasileiros que dispunham de condições psicológicas que os tornavam mais capazes de aprender: as crianças.

Amparado na tese de que a educação higiênica consiste na aquisição de hábitos higiênicos (ALMEIDA JÚNIOR, 1922), afırma que o futuro da humanidade dependeria da obediência da população às normas sanitárias. Tal obediência, porém, não era pensada como o cumprimento de conselhos externos ao indivíduo, visto que, nesse caso, tais conselhos não se instalariam como comportamentos. Almeida Júnior defendia que, por meio da educação higiênica seria possível promover hábitos higiênicos, permitindo que as próximas gerações não padecessem dos males sanitários dos quais a sua padecia.

\footnotetext{
7- A tese está organizada em introdução e seis capítulos, intitulados respectivamente: "0 saneamento e a educação"; "0 adulto e a creança"; "A escola primaria, eixo da sanitária"; "0 que faz, actualmente, a escola primária"; "Programmas e methodos"; e "Formação do professor”, além da conclusão. Nas citações literais, optei por manter a ortografia conforme utilizada nos documentos originais.

8- A tese de Almeida Júnior já foi analisada sob os auspícios da defesa da higiene por Rocha (2003a) e por Bertucci (2013).
} 
Para essa finalidade, a criança era preferida em relação ao adulto, porque somente ela era realmente educável. No que se referia à higiene, a maturidade intelectual do adulto era condição favorável apenas à "[...] comprehensão e obediência aos principios da higiene" (ALMEIDA JÚNIOR, 1922, p. 19). Já a criança predisporia de uma condição favorável à fixação de hábitos: a plasticidade dos tecidos nervosos. A esse respeito, Almeida Júnior (1922, p. 25) completa:

\begin{abstract}
Todos os nossos tecidos são plásticos, mas nenhum, nesse particular, sobreleva ao systema nervoso. A vaga nervosa abre, por si mesma, um leito, cuja profundidade augmenta à medida que os choques se repetem e se succedem as ondas. Cada influxo, transitando por uma via, é uma solicitação a mais para que o novo influxo siga no seu rasto. A permeabilidade das differentes vias vai, assim, crescendo pouco a pouco, e chegará o momento em que a resistência por ellas offerecida à corrente nervosa estará reduzida ao mínimo. Constituiu-se, então, o hábito.
\end{abstract}

Amparado nas discussões situadas no terreno da ciência da natureza infantil, inspiradas em Herbert Spencer, Gustave Le Bon e William James, Almeida Júnior argumentou em favor do modelamento de comportamentos por meio dos inumeráveis influxos que "[...] trafegam nas vias nervosas, esculpindo sulcos profundos e duradouros no sistema nervoso” (ALMEIDA JÚNIOR, 1922, p. 26).

Munido dessa representação acerca da infância como idade moldável e adaptável, o professor lançou sua proposta de educação higiênica, contrapondo-se àquilo que, em sua avaliação, era executado naquele momento: a higiene como instrução ensinada por regras e conselhos. 0 deslocamento que ele propôs promoveria um ensino mais ativo, por meio do qual a criança investigaria, descobriria, criticaria e agiria. Se os hábitos decorrem da “permeabilidade das vias nervosas”, é a ação que os gera (ALMEIDA JÚNIOR, 1922, p. 45).

Tais concepções sobre a natureza infantil permeadas pelo viés da formação de hábitos higiênicos podem ser vistas na Cartilha de higiene, de Almeida Júnior, publicada em 1923, pela Editora Monteiro Lobato, que se transformou em Companhia Editora Nacional. A proposta da cartilha, elaborada para ser utilizada nas escolas primárias, está explicitada na epígrafe que é destinada aos professores: promover a educação em higiene, assim como se fazia com a língua pátria e com os números. É possível notar, portanto, que Almeida Júnior iguala, em nível de importância, a higiene, a alfabetização e o ensino da matemática; saberes que despontam como cruciais para as escolas primárias ${ }^{9}$.

As lições da Cartilha de higiene são ilustradas e apresentam histórias narradas por um Saci ${ }^{10}$. Nelas são tematizados: o asseio pessoal (lavar as mãos, limpar as unhas, escovar

\footnotetext{
9- No inquérito promovido por Fernando de Azevedo (1937), em 1926, a convite d’O Estado de S. Paulo, Almeida Júnior voltaria a equiparar a importância dos conteúdos de higiene à língua materna e à matemática.

10- É notório o uso do Saci como personagem da cartilha, visto que essa figura do folclore brasileiro é reconhecida pelas travessuras e por fumar cachimbo. As ilustrações da Cartilha de higiene são de Belmonte, nome artístico de Benedito Barros Barreto (1896-1947), ilustrador, escritor e jornalista paulistano. Os questionamentos que podem ser feitos quanto ao uso do Saci na ilustração da cartilha se referem ao papel que Almeida Júnior teve (ou não) diante das decisões gráficas para a publicação do livro didático. É possível especular a influência de Monteiro Lobato nessa escolha, tendo em vista que, em 1921, publicou O Saci, voltado ao público infantil, bem como por estar à frente da editora homônima durante a edição da Cartilha de higiene. Além disso, Belmonte já havia ilustrado Jeca Tatu (1917), de Monteiro Lobato, o que pode explicar a relação entre 0 ilustrador e o editor. Até o momento, entretanto, não localizei informações que possam oferecer maiores aproximações a respeito do uso da ilustração do Saci na cartilha.
} 
os dentes e tomar banho); os cuidados com doenças infecciosas (tuberculose, tracoma, maleita e febre tifoide); e a importância de hábitos saudáveis (ferver leite, ferver água, comer verduras e frutas, usar o banheiro regularmente, dormir em ambiente ventilado, praticar exercícios, usar ambiente claro para ler, respirar adequadamente, não beber álcool e não fumar).

Do modo como estão apresentadas, as histórias têm um tom modelador de comportamentos: condenam hábitos tomados como prejudiciais (os quais parecem ser representativos daquilo que era comum entre a população pobre da época) e elogiam aqueles considerados desejáveis. Com isso, produz-se uma narrativa que faz uso de imagens e de discursos que permitem compreender o objetivo da cartilha: intervir politicamente sobre a população (ROCHA, 2011).

Mais do que isso, encenando os interditos e as prescrições higiênicas relativas aos cuidados cotidianos consigo e com o meio, a cartilha cumpre com um papel de dispositivo político-pedagógico de disciplinarização de condutas. Conduz a narrativa por meio das legendas, enunciando ensinamentos, conselhos e, até mesmo, convites para a vigia de si e dos outros em relação aos corpos e aos modos de agir. Com isso, Almeida Júnior contempla seu propósito de uma educação higiênica ativa, um ensino que não apenas disciplina, mas que incentiva as crianças a serem mais interventoras na condução de suas vidas cotidianas também dentro de suas casas.

A Cartilha de higiene teve dezessete edições entre 1923 e 1940, o que permite inferir o longo período em que foi utilizada e adotada nas escolas. A título de exemplo, a décima edição da cartilha é de 1928, ou seja, em cinco anos, dez novas edições foram publicadas. Cabe destacar também a circulação da cartilha em escolas de São Paulo e do Ceará ${ }^{11}$, provavelmente devido à influência de Lourenço Filho, que havia assumido, em 1922, a direção da Instrução Pública do Ceará.

A preocupação com hábitos sadios e com a organização de espaços escolares higiênicos estava presente não somente na Cartilha de higiene, mas também nas reflexões de Almeida Júnior quando participou de encontros que envolviam médicos e educadores. Em 1926, durante o Terceiro Congresso Brasileiro de Higiene, que ocorreu em São Paulo, Almeida Júnior abordou a necessidade de assumir tom catequizador para colocar em prática princípios higiênicos tão necessários à escolarização. Um dos princípios básicos da prática da higiene na escola, segundo ele, era, por exemplo, a inclusão de chuveiros no espaço escolar, visto que algumas crianças não tinham esses objetos em suas casas. Assim, caberia à escola ser repensada, do ponto de vista da arquitetura, para incentivar o hábito do banho (VIVIANI; MARCHAN, 2008).

A alimentação é outro tema abordado na Cartilha de higiene, bem como em "A alimentação na idade escolar e pré-escolar", apresentado no Primeiro Congresso Brasileiro de Higiene, sediado no Rio de Janeiro, em 1923. 0 trabalho também foi publicado sob a forma de artigo em Boletim do Instituto de Higiene, saído a lume, no mesmo ano, no volume 15. É interessante notar a republicação integral do texto, o que permite constatar que a participação do professor e médico nas conferências educacionais era pensada como

11- Como era comum em muitos livros didáticos dessa época, a informação a respeito da circulação da cartilha está disponível na segunda capa do livro. 
forma de situar as conquistas e posicionar os avanços dos paulistas em relação à educação higiênica, assim como identificar o lugar que Almeida Júnior ocupava como porta-voz do que se desenvolvia no âmbito do Instituto de Higiene.

Além desse trabalho, Almeida Júnior também apresentou "Qual a maneira mais pratica de organizar a assistencia à criança, na idade escolar?" e "Clinicas de nutrição e merendas para escolares" durante a Conferência Nacional de Proteção à Infância, sediada em São Paulo, em 1933. Tais escritos permitem inferir que a alimentação de fato era tema para o qual Almeida Júnior dirigia reflexões, e isso pode ser explicado a partir da constatação, já apresentada na tese de 1922, de que a maior causa de mortalidade infantil se devia às más condições nutricionais das crianças.

Tanto no texto de 1923 quanto nos de 1933 a proposta de Almeida Júnior era refletir sobre as condições de armazenamento dos alimentos trazidos pelos alunos para as escolas, as condições de alimentação no espaço educacional e relacionar, com isso, as orientações acerca do bom andamento das condições higiênicas dos escolares, visando à saúde dos alunos.

Almeida Júnior (1923, 1933a, 1933b) explora a ideia de que a alimentação é um importante veículo de moléstias e que fiscalizar os alimentos, cuidar do tratamento da água e combater a proliferação das moscas seriam de grande valia no espaço escolar. Os textos das conferências, devido à natureza e à finalidade a que atendiam, visavam apresentar resultados de investigações cientificamente respaldadas sobre temas e, desse modo, as propostas apresentadas são endossadas por experiências desenvolvidas por pesquisadores de outros países.

Os cuidados com a alimentação, conforme explorados nos escritos de Almeida Júnior, são tomados dentro da função que cumpriam diante do controle do crescimento infantil e de sua influência para o desenvolvimento da criança. Desse ponto de vista, junto de outros cuidados, como o asseio, a prática de exercícios físicos, o não abuso de substâncias químicas, como álcool e tabaco, a alimentação teria papel de destaque na infância, tendo em vista que a causa mais comum de mortalidade infantil, segundo esse professor, era o "desvio alimentar" (ALMEIDA JÚNIOR, 1922, p. 14).

A partir dessas constatações, Almeida Júnior tensiona a representação de uma infância desvalida que precisa ser regenerada (por meio de hábitos higiênicos) e um padrão de normalidade que deve ser encontrado nos escolares. Entre o tipo e o desvio, os saberes sobre higiene tornam-se um artefato político-pedagógico, denotando o tratamento disciplinador e higienizador dado àquelas crianças que escapavam aos registros da normalidade que eram produzidos (ROCHA, 2015).

É possível constatar, portanto, que na tese, na Cartilha de higiene e em outros escritos das décadas de 1920 e 1930 que tematizam a higiene, Almeida Júnior apresentou um programa de educação higiênica que seria executado mediante a formação do hábito; resultado da soma do ensino de conteúdos de higiene à exposição perene da criança a práticas higiênicas e à presença modelar dos professores. Assim, compunham o escopo das ações combinadas às quais a criança era sujeita na proposta de educação higiênica defendida por Almeida Júnior: a revista da escola e da sala de aula junto do professor, a inspeção de seu corpo quanto à altura, ao peso, à dentição, às acuidades visual e auditiva 
e a inquisição quanto aos costumes e hábitos familiares no âmbito doméstico (ALMEIDA JÚNIOR, 1922, 1923, 1933a, 1933b).

Esses aprendizados e a normatização de comportamentos definidos como saberes elementares a serem ensinados nas escolas primárias estão mobilizados na Cartilha de higiene à medida que ela é utilizada como um dispositivo por meio do qual se enceta o programa orientador de uma vida desejável, assim como quando ela apresenta como exemplificadoras as relações familiares, a habitação, os cuidados com o corpo, com a saúde; mas, no limite, também quando orienta, ao expor, em tom de desaprovação, os resultados de uma vida na qual não há saúde, não há boa relação familiar, mas há vícios e doença.

Ademais, é preciso considerar que as ações de inspeção, propostas por Almeida Júnior, que os professores deveriam desenvolver tanto no âmbito escolar, como medir o peso e a altura dos alunos, orientação nutricional, quanto ao combate a doenças, evidenciam o conjunto de saberes que deveria ser apropriado pelos professores no âmbito do programa de educação higiênica.

Devido ao fato de os professores das escolas primárias desempenharem papel crucial junto à divulgação da educação higiênica, os cuidados com a formação e a apropriação de saberes específicos de áreas como a saúde, a higiene e a biologia, tornaram-se preponderantes. Tratava-se, portanto, de reformular programas, conteúdos e métodos na formação de professores, direcionando o olhar atento à higiene infantil e escolar, à puericultura e à biologia escolar.

\section{Renovação de métodos e conteúdos para a formação de professores}

Em sua tese, Almeida Júnior (1922) defende que o professor primário era a força motriz da educação; nesse sentido, sua proposta acerca da formação de hábitos higiênicos se fundava na concepção de que, a partir de atitudes modelares, o professor poderia ser um bom exemplo aos alunos sobre os modos de agir. Essa exemplaridade deveria somarse à formação de hábitos cotidianos de higiene para a promoção de comportamentos considerados adequados.

Sua proposta de ensino de higiene sustentava-se na organização dos saberes da escola normal, que compreendiam conteúdos como anatomia, psicologia, história natural, noções de zoologia, fisiologia e química, e projetava a inclusão do ensino de higiene no quarto ano, com aulas que durariam duas horas semanais. Ao todo, com cinquenta aulas, Almeida Júnior considerava ser possivel fornecer os saberes com uma amplitude necessária para amparar os normalistas do ponto de vista teórico e prático.

A autonomia do professor que ensinaria higiene é tomada como essencial para o trabalho de planejamento das atividades didáticas. Para tanto, ele assume como crucial a garantia das condições de seguir com unidade e eficiência um programa oficial, desde que ele propusesse um ensino de higiene que visasse às "applicações dessa disciplina à escola e à vida pratica”, e compreendesse, segundo Almeida Júnior (1922, p. 59-60), os seguintes saberes: 
a) Gravidade, etiologia e prophylaxia das principais molestias infecto-contagiosas;

b) Hygiene pessoal: a respiração, a alimentação, o asseio, o vestuário e o exercicio;

c) Hygiene domiciliar, urbana e rural: a posição da casa, o asseio, a ventilação, a iluminação;

d) Hygiene urbana: as ruas, abastecimento de agua, os esgottos, o lixo;

e) Hygiene da primeira infancia: cuidados para com as creanças, sua alimentação, seu desenvolvimento;

f) Hygiene escolar: a escola, o regimen de aulas, o alumno.

No texto introdutório da Cartilha de higiene, "Educação higiênica", Almeida Júnior se dirige aos professores e acentua o caráter prático do trabalho que deveria ser desenvolvido com vistas a inculcar nas crianças "hábitos úteis, referentes ao asseio, à alimentação, ao exercício” (ALMEIDA JÚNIOR, 1922, p. 60).

Mas são em seus manuais pedagógicos, como Noções de puericultura, Elementos de anatomia e fisiologia humanas e Biologia educacional, que os saberes sobre higiene são apresentados de modo a cumprir com a função anunciada por ele: fornecer um "convívio diuturno com a ciência" para aperfeiçoar a "técnica e fornecer matéria prima substancial e pura” (ALMEIDA JÚNIOR, 1966, p. 9). Conforme Viviani e Bueno (2006) analisam, a defesa acerca de um modelo de formação de professores que estivesse calcado em cultura geral associada a conteúdos que oferecessem uma base biológica cientificamente sólida e com ciências consideradas fundamentos da educação já estava presente no estado de São Paulo desde a Reforma de Sampaio Dória, em 1920.

O livro Noções de puericultura foi publicado em 1927 e escrito em coautoria com Mario Mursa; sobre o último, ex-diretor do Hospital de Crianças de Indianápolis - conforme consta na página de rosto do livro -, não sendo possível localizar mais informações. 0 livro tem anunciado em sua capa que se destina às mães e às escolas normais, e em seu prefácio fica bastante evidente a defesa dos autores quanto às finalidades que têm com o manual, e o zelo acerca do caráter prático do livro ganha relevo, como pode se notar no excerto a seguir:

A feição didactica, simples e methodica, que lhe imprimimos, isenta de artificios literários, pareceu-nos a mais consetanea com os seus fins. Queremos convencer com clareza. A muitos se afigurará que nos excedemos na parte sicentifica. Suppomos que não. Um livro apenas de regras práticas, sem consignar nunca os "porquês", mesmo quando estes estão ao alcance da cultura leiga, não deixaria transparecer, como queremos, que cada preceito estabelecido nasce de um principio scientífico, e não do capricho ou da fantasia de quem o consagrou. (ALMEIDA JÚNIOR; MURSA, 1927, p. VII-VIII).

Em suas 193 páginas, divididas em dezenove capítulos, Noções de puericultura aborda: a anatomia e a fisiologia do corpo humano; a mortalidade infantil; os cuidados com a higiene pré-natal e com o recém-nascido, com a alimentação, a amamentação, a alimentação natural e artificial, com vestimentas; e noções de profilaxia de algumas doenças, como sarampo, varíola, coqueluche, verminoses, tuberculose e raquitismo.

Conforme Morando e Souza (2019) analisam, no começo do século XX, a preocupação com o corpo social da criança esteve presente nos discursos médico- 
educacionais. A puericultura, como a intersecção entre a higiene e a eugenia, se voltou para a higienização da sexualidade e para a valorização da maternidade com o propósito de produzir hábitos e condutas em relação à vida e aos cuidados com a criança durante a primeira infância. Objetificando e colocando a maternidade sob a tutela do Estado, o discurso médico inventou a boa mãe e, desse modo, ordenou, prescreveu e condenou condutas que perpassavam a vida das mulheres.

Desse ponto de vista, os manuais didáticos podem ser considerados instâncias pedagógicas que divulgam saberes, normatizam condutas, produzem corpos desejáveis e constroem subjetividades.

Noções de puericultura foi publicado pelo Instituto D. Anna Rosa, associação criada em 1874 com a finalidade de promover a proteção à infância desvalida por meio de internato, mas que também funcionou como editora. No âmbito dessa casa de abrigo para crianças órfãs, Almeida Júnior desenvolveu um programa nutricional, mencionando sobre a alimentação pré-escolar e escolar (ALMEIDA JÚNIOR, 1923).

A segunda edição do livro foi publicada em 1933. Pelo que foi possível apurar, apesar da maior quantidade de páginas na segunda edição em relação à primeira, ambas têm o mesmo conteúdo. A terceira edição do livro, publicada em 1938, tem o título alterado para 0 livro das mamães: noções de puericultura, com mudanças em relação à editora, que passa a ser a Companhia Editora Nacional. Não tive acesso ao exemplar e, portanto, não é possível afirmar se houve alterações de conteúdo ou se foram apenas alterações gráficas e editoriais.

0 manual Elementos de anatomia e fisiologia humanas, segundo consta em sua capa, era destinado aos ginásios e às escolas normais. Publicado em 1931, o manual de cerca de quatrocentas páginas pertencia à série Livros Didáticos da Biblioteca Pedagógica da Companhia Editora Nacional. Acessei a quinta edição do livro, a qual tem onze partes que abordam: as células, o aparelho locomotor, a alimentação, a digestão, o sangue, a circulação, a respiração, as glândulas, o sistema nervoso, o sentido, a fonação e a linguagem e a evolução do indivíduo.

No prefácio à primeira edição do livro, Almeida Júnior anuncia sua intenção ao escrever o livro: fazê-lo claro para a mocidade. Por já ter tido experiência com os jovens, ele dizia saber como se dirigir a eles. No prefácio da quarta edição, publicada em 1935, e que se mantém na quinta edição de 1938, Almeida Júnior pontua as modificações que realizou no livro, com a exclusão de tópicos sobre biologia geral e a inclusão de outros, os quais abordam assuntos como: atividade muscular, ração humana, indicações higiênicas e bebidas alcoólicas, por exemplo.

Esse manual teve 37 edições, a última datando de 1973, o que evidencia a circulação durante um longo período. E, a esse respeito, algo é digno de nota. Noções de puericultura teve uma circulação menor e restrita a três edições - algo que pode estar relacionado com a editora pela qual as primeiras edições do livro vieram a lume -, e Biologia educacional teve 22 edições, as quais foram publicadas entre 1939 e 1969, atingindo um total de 120 mil exemplares (VIVIANI; BUENO, 2006). Esse alcance dos manuais publicados é bastante representativo do uso de seus materiais com finalidades pedagógicas. De algum modo, Elementos de anatomia e fisiologia humanas e Biologia educacional foram incorporados 
com muito mais aderência aos programas de disciplinas biológicas em cursos de formação de professores.

Ademais, é preciso registrar também que ambos os manuais foram lançados pela Companhia Editora Nacional como parte integrante da Biblioteca Pedagógica Brasileira. Biologia educacional estava incluído na seção "Atualidades pedagógicas" e Elementos de anatomia e fisiologia humanas na série Livros Didáticos. Tal biblioteca foi coordenada por Fernando de Azevedo entre 1931 e 1946 de modo a articular seu projeto político ao empreendimento comercial da editora, tendo em vista a formação de professores tanto do ponto de vista profissional como cultural (VIVIANI; BUENO, 2006).

De acordo com Gandini (2010), o sucesso desse manual também pode estar relacionado com a própria condição de Almeida Júnior como professor de biologia educacional no Instituto de Educação Caetano de Campos. Como se nota, os impressos pedagógicos produzidos por esse professor eram legitimados pelos cargos que ele ocupava. Porém, mais do que isso, o conjunto de educadores com os quais ele se relacionava também contribuiu para que suas ideias circulassem e fossem endossadas editorialmente por intelectuais que disputavam a cena educacional naquele momento.

Com 507 páginas, Biologia educacional explora os fatores biológicos que determinam "as diferenças e as variações individuais na espécie humana, e dos meios com que o educador pode atuar sôbre êsses fatores, a fim de atingir, para o indivíduo, o máximo de saúde e de eficiência física e mental" (ALMEIDA JÚNIOR, 1966, p. 19). Como disciplina que substituiu Biologia e Higiene das Escolas Normais, a Biologia Educacional foi implantada, em São Paulo, a partir do Código de Educação de 1933, elaborado por Fernando de Azevedo. Como já mencionado anteriormente, Almeida Júnior colaborou na produção dessa reforma.

Organizado em cinco partes, o livro apresenta primeiramente aquilo que é denominado como parte fundamental da biologia educacional (vida e evolução, genética, mesologia e atividade funcional) e, na sequência, a parte prática (eugenia e eutenia dentro desta, estavam incluídas a higiene e a educação).

Os esforços de Almeida Júnior se dão no sentido de propor formas de otimizar as condições físicas, mentais, psicológicas e morais dos indivíduos, por meio de interferências sociais e educativas - o exercício físico e mental e a vida pautada em preceitos eugênicos e higiênicos. Com isso, aprender a importância de pesar as crianças, medir a estatura, conseguir identificar sintomas e tratar doenças compõem aprendizados e preceitos sobre higiene que passam a ser tomados como indispensáveis à prática docente.

Desse ponto de vista, uma aprendizagem prática, porém consolidada em sólidos conhecimentos científicos, se torna defensável. Tanto que, no Instituto de Higiene, Almeida Júnior também já propunha iniciativas de atividades que visavam a formação dos professores em higiene; nestas, predominavam demonstrações, exercícios e as noções de puericultura.

Como se nota, o projeto higiênico para formação de professores elaborado por Almeida Júnior se alicerçava no oferecimento de conteúdos científicos e fundamentais para o entendimento da educação. A defesa da importância dos professores decorria de uma visão segundo a qual o aparelho educacional seria um sistema capilar por meio 
do qual o Estado distribuiria civilização à população. Assim, capacitar os professores equivaleria à missão de levar higiene para a escola primária.

A proposta de fazer circular os saberes acerca da educação higiênica, de acordo com Almeida Júnior, consistia em oferecer um suporte conceitual e prático que capacitasse os professores primários no âmbito das Escolas Normais e os auxiliasse com uma caixa de ferramentas.

\section{Saberes sobre higiene nos escritos de Almeida Júnior}

Neste artigo, discuti as intersecções que Almeida Júnior promoveu entre a medicina e a educação visando enfrentar os dilemas educacionais e sanitários durante as primeiras décadas do século XX. Utilizando estrategicamente os impressos pedagógicos e a sua atuação como médico, professor e administrador da educação, Almeida Júnior defendeu que a educação higiênica consistia em formar hábitos higiênicos.

Apropriando-se das discussões da ciência da natureza infantil e da plasticidade cerebral, Almeida Júnior destinou seu programa higiênico às crianças. Assim, nos manuais de ensino que escreveu, abordou temas de modo a produzir condutas desejadas em crianças e em suas famílias. Às suas representações acerca da infância, Almeida Júnior articulou suas proposições acerca da finalidade da escola e da formação docente. Versando sobre o ensino da puericultura, da eugenia e abordando fundamentos biológicos da educação, o professor buscou incorporar em seus impressos conhecimentos científicos sólidos e amparados em metodologias mais ativas.

Os saberes sobre higiene destinados às escolas primárias, conforme tematizados por Almeida Júnior, assim como os usos, as finalidades e os leitores pretendidos, permitiram explorar não apenas os propósitos normatizadores de condutas e de práticas pedagógicas, mas também a finalidade da escola primária dentro de seu programa. A amplitude de formatos e de públicos a que seus impressos se destinaram também merece destaque: professores em formação, intelectuais, médicos, mães e alunos das escolas primárias estiveram dentro do grupo de leitores almejados por Almeida Júnior.

Ademais, foi possivel situar também o trânsito e a relação profissional intensa de Almeida Júnior com um conjunto de intelectuais que ocupava a cena educacional e médica no período em questão. Nesse local de intersecção, ele defendeu e teve endossadas suas defesas acerca do saneamento da sociedade pela educação.

\section{Referências}

ALMEIDA JÚNIOR, Antonio Ferreira de. Alimentação na idade escolar e pré-escolar. In: CONGRESSO BRASILEIRO DE HIGIENE, 1., 1923, Rio de Janeiro. Annaes [... .]. Rio de Janeiro: [s. n.], 1923. p. 113-118.

ALMEIDA JÚNIOR, Antonio Ferreira de. Biologia educacional: noções fundamentais. 19. ed. São Paulo: Companhia Editora Nacional, 1966.

ALMEIDA JÚNIOR, Antonio Ferreira de. Cartilha de higiene: para uzo nas escolas primárias. 10. ed. São Paulo: Companhia Editora Nacional, 1928. 
ALMEIDA JÚNIOR, Antonio Ferreira de. Clinicas de nutrição e merendas para escolares. In: CONFERÊNCIA NACIONAL DE PROTEÇÃO À INFÂNCIA, 1., 1933, Rio de Janeiro. Annaes [.. . ]. São Paulo: Imprensa Oficial do Estado, 1933a. p. 1-10.

ALMEIDA JÚNIOR, Antonio Ferreira de. Elementos de anatomia e fisiologia humanas. 5. ed. São Paulo: Companhia Editora Nacional, 1938.

ALMEIDA JÚNIOR, Antonio Ferreira de. 0 saneamento pela educação. 1922. Tese (Doutorado em Medicina) - Faculdade de Medicina e Cirurgia de São Paulo, São Paulo, 1922.

ALMEIDA JÚNIOR, Antonio Ferreira de. Qual a maneira mais prática de organizar a assistencia à criança, na idade escolar? In: CONFERÊNCIA NACIONAL DE PROTEÇÃO À INFÂNCIA, 1., 1933, Rio de Janeiro. Annaes [...]. São Paulo: Imprensa Oficial do Estado, 1933b. p. 1-8.

ALMEIDA JÚNIOR, Antonio Ferreira de; MURSA, Mário. Noções de puericultura: para as mães e para as escolas. São Paulo: Instituto D. Anna Rosa, 1927.

AZEVEDO, Fernando de. 0 que pensa 0 dr. A. Almeida Junior. In: AZEVEDO, Fernando de. A educação pública em São Paulo: problemas e discussões: inquérito para "O Estado de S. Paulo", em 1926. São Paulo: Companhia Editora Nacional, 1937. p. 39-55.

BERTUCCI, Liane Maria. Dois momentos, um ideal: educação e saúde para formar o brasileiro: São Paulo, 1918; Paraná, 1928. In: CONGRESSO BRASILEIRO DE HISTÓRIA DA EDUCAÇÃO, 4., 2006, Goiânia. Anais [...]. Goiânia: UCG, 2006. p. 1-7.

BERTUCCI, Liane Maria. Sanear a raça pela educação: teses da Faculdade de Medicina e Cirurgia de São Paulo, início dos anos 1920. In: MOTA, André; MARINHO, Maria Gabriela S. M. C. (org.). Eugenia e história: ciência, educação e regionalidades. São Paulo: USP: Faculdade de Medicina: UFABC: CD.G, 2013. v. 4. p. 219-238. (Medicina, Saúde e História).

CARVALHO, Marta Maria Chagas de. Molde nacional e forma cívica: higiene, moral e trabalho no projeto da Associação Brasileira de Educação (1924-1931). Bragança Paulista: EdUSF, 1998.

CARVALHO, Marta Maria Chagas de. Pedagogia moderna, pedagogia da escola nova e modelo escolar paulista. In: CARVALHO, Marta Maria Chagas de; PINTASSILGO, Joaquim (org.). Modelos culturais, saberes pedagógicos, instituições educacionais: Portugal e Brasil, histórias conectadas. São Paulo: USP: Fapesp, 2011. p. 185-212.

CHARTIER, Roger. 0 mundo como representação. Estudos Avançados, São Paulo, v. 5, n. 11, p. 173-191, 1991.

GANDINI, Raquel. Almeida Júnior. Recife: Fundação Joaquim Nabuco: Massangana, 2010.

GANDINI, Raquel. Passagens da trajetória de Antonio F. de Almeida Júnior na educação paulista: do patrimonialismo à escola republicana. 2005. Tese (Livre-docência em Educação) - Faculdade de Educação, Universidade Estadual de Campinas, Campinas, 2005. 
HÉBRARD, Jean. A escolarização dos saberes elementares na época moderna. Teoria \& Educação, Porto Alegre, n. 2, p. 65-110, 1990.

MORAND0, André; SOUZA, Nadia Geisa Silveira de. A (re)invenção da boa mãe em um manual de puericultura no Brasil dos anos 1930. Revista Histedbr Online, Campinas, v. 19, p. 1-20, 2019.

ROCHA, Heloísa Helena Pimenta. A higienização dos costumes: educação escolar e saúde no projeto do Instituto de Hygiene de São Paulo (1918-1925). Campinas: Mercado das Letras: Fapesp, 2003a.

R0CHA, Heloísa Helena Pimenta. Alfabetização, saneamento e regeneração nas iniciativas de difusão da escola primária em São Paulo. Pro-Posições, Campinas, v. 22, n. 2, p. 151-172, 2011.

ROCHA, Heloísa Helena Pimenta. Educação escolar e higienização da infância. Cadernos Cedes, Campinas, v. 23, n. 59, p. 39-56, 2003b. Disponível em: http://www.scielo.br/pdf/ccedes/v23n59/a04v23n59.pdf. Acesso em: 14 mar. 2018.

ROCHA, Heloísa Helena Pimenta. Entre o exame do corpo infantil e a conformação da norma racial: aspectos da atuação da Inspeção Médica Escolar em São Paulo. História Ciência e Saúde - Manguinhos, Rio de Janeiro, v. 22, n. 2, p. 371-390, 2015. Disponível em: http://www.scielo.br/pdf/hcsm/v22n2/0104-5970hcsm-22-2-371.pdf. Acesso em: 9 maio 2018.

VIVIANI, Luciana Maria. A biologia necessária: formação de professoras e escola normal. Belo Horizonte: Argumentvm; São Paulo: Fapesp, 2007.

VIVIANI, Luciana Maria. Formação de professoras e Escolas Normais paulistas: um estudo da disciplina Biologia Educacional. Educação e Pesquisa, São Paulo, v. 31, n. 2, p. 201-213, 2005. Disponível em: https://www. scielo.br/j/ep/a/Ld9hmXHzNDV9V4sZkHsy6fv/?format=pdf\&lang=pt. Acesso em: 22 maio 2020.

VIVIANI, Luciana Maria; BUENO, Belmira Oliveira. A biologia educacional nas escolas normais paulistas: uma disciplina da eficiência física e mental. Revista Portuguesa de Educação, Braga, v. 19, n. 1, p. 43-65, 2006.

VIVIANI, Luciana Maria; MARCHAN, Geisiele da Silva. Almeida Júnior e a produção de modelos paulistas de ensino higiênico e renovador: participações em Encontros Científicos das décadas de 1920 a 1940. In: CONGRESSO BRASILEIRO DE HISTÓRIA DA EDUCAÇÃO, 5., 2008, Aracaju. Anais [...]. Aracaju: Universidade Tiradentes, 2008. p. 1-16.

Recebido em: 02.06.2020

Aprovado em: 22.07.2020

Angélica Pall Oriani é doutora em educação pela Universidade Estadual Paulista (Unesp) e pós-doutora pela mesma universidade. Atualmente é professora em cursos de licenciatura do Centro Universitário Sagrado Coração (Bauru/SP). 